\title{
Catalase Influence in the Regulation of Coronary Resistance by Estrogen: Joint Action of Nitric Oxide and Hydrogen Peroxide
}

\author{
Paulo C. Schenkel, Rafael O. Fernandes, Vinícius U. Viegas, Cristina Campos, \\ Tânia R. G. Fernandes, Alex Sander da Rosa Araujo, and Adriane Belló-Klein \\ Laboratório de Fisiologia Cardiovascular, Departamento de Fisiologia, Instituto de Ciências Básicas da Saúde, \\ Universidade Federal do Rio Grande do Sul, Sarmento Leite 500, Bairro Farroupilha, 90050-170 Porto Alegre, RS, Brazil \\ Correspondence should be addressed to Adriane Belló-Klein; belklein@ufrgs.br
}

Received 22 November 2013; Accepted 25 December 2013; Published 6 February 2014

Academic Editor: Neelam Khaper

Copyright (C) 2014 Paulo C. Schenkel et al. This is an open access article distributed under the Creative Commons Attribution License, which permits unrestricted use, distribution, and reproduction in any medium, provided the original work is properly cited.

\begin{abstract}
We tested the influence of estrogen on coronary resistance regulation by modulating nitric oxide (NO) and hydrogen peroxide $\left(\mathrm{H}_{2} \mathrm{O}_{2}\right)$ levels in female rats. For this, estrogen levels were manipulated and the hearts were immediately excised and perfused at a constant flow using a Langendorff's apparatus. Higher estrogen levels were associated with a lower coronary resistance, increased nitric oxide bioavailability, and higher levels of $\mathrm{H}_{2} \mathrm{O}_{2}$. When oxide nitric synthase blockade by L-NAME was performed, no significant changes were found in coronary resistance of ovariectomized rats. Additionally, we found an inverse association between NO levels and catalase activity. Taken together, our data suggest that, in the absence of estrogen influence and, therefore, reduced $\mathrm{NO}$ bioavailability, coronary resistance regulation seems to be more dependent on the $\mathrm{H}_{2} \mathrm{O}_{2}$ that is maintained at low levels by increased catalase activity.
\end{abstract}

\section{Introduction}

Decreased levels of estrogen play a critical role in heart disease development after menopause. The loss of ovarian hormones has a widespread adverse impact, increasing the risk of cardiovascular events, such as myocardial infarction (MI) [1-3].

The ischemic insult caused by MI can be increased during the early moments of reperfusion, referred to as ischemia/ reperfusion (I/R) injury [4]. Moreover, myocardial cells tissue damage is aggravated by producing reactive oxygen species (ROS) under ischemic conditions by mitochondrial electron transport chain or by enzymes such as NADPH oxidase, xanthine oxidase, and nitric oxide synthase (NOS) [5].

Under I/R situations, such as in acute MI, endothelial injury decreases the production of nitric oxide (NO) [6], and NOS can become a source of superoxide anion $[7,8]$. This process is termed NOS uncoupling. Moreover, NO produced from NOS can react with superoxide anion decreasing NO bioavailability and generating the potent oxidant, peroxynitrite (ONOO-) [9]. On the other hand,
Yada et al. demonstrated that endogenous hydrogen peroxide $\left(\mathrm{H}_{2} \mathrm{O}_{2}\right)$ contributes to coronary vasodilatation during $\mathrm{I} / \mathrm{R}$ in vivo as a compensatory mechanism for the NO loss [10]. And, according to Cosentino et al. [11], $\mathrm{H}_{2} \mathrm{O}_{2}$ can be involved in vasorelaxation during uncoupling of $\mathrm{NO}$ synthesis. Moreover, it has been shown that $\mathrm{H}_{2} \mathrm{O}_{2}$ has a critical role as a signaling molecule for cardiac remodeling, probably due to its greater stability and permeability as compared to other ROS. In this context, the $\mathrm{H}_{2} \mathrm{O}_{2}$ levels modulation by antioxidant enzyme catalase (CAT) seems to play an important role in cardiovascular function [11].

Estrogen therapy (ET) has been considered as a means to reduce cardiovascular risk in postmenopausal women [1] and in animals submitted to I/R injury [12-14]. Furthermore, it has been reported that ET improves NO-mediated vasodilatation in ovariectomized rats [15]. However, the ET effects on $\mathrm{H}_{2} \mathrm{O}_{2}$ concentrations and its repercussion in coronary tone are not known.

Therefore, the aim in this study was to verify if the influence of estrogen over coronary resistance is modulated by hydrogen peroxide concentrations through catalase 
activity control. Another aim of this study was to determine, through the NOS blockade, whether NO participates of this mechanism.

\section{Methods}

2.1. Animals. Twenty-nine female Wistar rats (60 days, $200 \pm$ $20 \mathrm{~g}$ ) were obtained from the Central Animal House at Universidade Federal do Rio Grande do Sul, Brazil. The animals were housed in plastic cages (four animals each) and received water and food ad libitum. They were maintained under standard laboratory conditions (controlled temperature of $21^{\circ} \mathrm{C}, 12$ hours light/dark cycle). They were divided into three groups: SHAM, that was submitted to a sham surgery of bilateral ovariectomy; OVX, which was ovariectomized; and OVX $+\mathrm{E}_{2}$, that was ovariectomized and received $17 \beta$ estradiol replacement. Each group was divided into two groups for the isolated heart perfusion, according to the perfusion solution utilized (Tyrode or Tyrode + L-NAME). Thus, the six experimental groups were TYRODE-SHAM $(n=5)$; L-NAME-SHAM $(n=4)$; TYRODE-OVX $(n=6)$; L-NAME-OVX $(n=4)$; TYRODE-OVX $+\mathrm{E}_{2}(n=4)$; L$\mathrm{NAME}-\mathrm{OVX}+\mathrm{E}_{2}(n=4)$.

2.2. Ethical Approval. The experimental design was approved by the Committee on Animal Care and Use of the Universidade Federal do Rio Grande do Sul, following the Principles of Laboratory Animal Care published by the Council for International Organizations of Medical Science.

2.3. Ovariectomy (OVX). The rats were anesthetized (ketamine $90 \mathrm{mg} \mathrm{kg}^{-1}$; xylazine $10 \mathrm{mg} \mathrm{kg}^{-1}$ i.p.) and bilateral ovariectomy or sham operation was performed. After a week, the animals were submitted to a $17 \beta$-estradiol replacement or replacement simulation.

2.4. $17 \beta$-Estradiol Therapy. Briefly, $15 \mathrm{~mm}$ medical grade tubing $(1.02 \mathrm{~mm}$ i.d. $\times 2.16 \mathrm{~mm}$ o.d.) was filled with $10 \mu \mathrm{L}$ of $5 \%(\mathrm{w}: \mathrm{v}) 17 \beta$-estradiol (Sigma Chemical Co., St. Louis, MO, USA) in sunflower oil and sealed with silicone. Capsules were soaked in sterile saline overnight and implanted subcutaneously between the scapulae under anesthesia. Sham animals were implanted with capsules containing just sunflower oil [16].

2.5. $17 \beta$-Estradiol Concentration. Blood samples were collected 28 days after ovariectomy surgery by the retrorbital venous plexus and immediately centrifuged at $1000 \mathrm{~g}$ for $10 \mathrm{~min}$. The plasma $17 \beta$-estradiol concentration was estimated by chemiluminescence using the Immunolite 2000 apparatus (Biomedical Technologies Inc. Strougerton, MA, USA) at Weinmann Clinical Analysis Laboratory. The results were expressed as pg $\mathrm{mL}$ plasma ${ }^{-1}$.

2.6. Estrous Cycle Determination. In female rats not submitted to ovariectomy, cycle determination was started at the 28th day of the experimental protocol. The cycle of each female rat was determined by observation of vaginal smears, which were taken using plastic tip. Saline was placed on the vaginal opening, aspirated, and then placed on a microscopic slide. Animals in the diestrus phase were used [17].

2.7. Experimental Protocol. After 28 days of the ovariectomy, the rats were killed by decapitation and the hearts were immediately excised and perfused at a constant flow using a Langendorff's apparatus [18]. After the connection of aorta and insertion of the balloon into left ventricle, the hearts were stabilized for $20 \mathrm{~min}$ with an end-diastolic pressure set to about $10 \mathrm{mmHg}$. Animals that did not show stable conditions at the end of this period were discarded. Global ischemia was induced by suspending the coronary flow for $30 \mathrm{~min}$, and after that hearts were reperfused for $20 \mathrm{~min}$.

2.8. Isolated Heart Perfusion. The hearts were rapidly excised through a median sternotomy and aorta was retrogradely perfused (Langendorff model) using a Langendorff apparatus (Hugo Sachs Electronics, March-Hugstetten, Germany). The isolated hearts were perfused with two modified Tyrode solutions. One solution containing $120 \mathrm{mmol} \mathrm{L}^{-1}$ $\mathrm{NaCl}, 5.4 \mathrm{mmol} \mathrm{L}^{-1} \mathrm{KCl}, 1.8 \mathrm{mmol} \mathrm{L}^{-1} \mathrm{MgCl}_{2}, 1.25 \mathrm{mmol} \mathrm{L}^{-1}$ $\mathrm{CaCl}_{2} \cdot 2 \mathrm{H}_{2} \mathrm{O}, 2 \mathrm{mmol} \mathrm{L}^{-1} \mathrm{NaH}_{2} \mathrm{PO}_{4}, 27 \mathrm{mmol} \mathrm{L}{ }^{-1} \mathrm{NaHCO}_{3}$, $1.8 \mathrm{mmol} \mathrm{L}^{-1} \mathrm{Na}_{2} \mathrm{SO}_{4}$, and $11 \mathrm{mmol} \mathrm{L}^{-1}$ glucose, and, other containing similar composition plus $100 \mu \mathrm{mol} \mathrm{L}{ }^{-1} \mathrm{~N}^{\omega}$-nitroL-arginine methyl ester (L-NAME) in a doses capable to inhibit all NOS isoforms [19]. Both solutions were equilibrated with a $95 \%$ oxygen and $5 \%$ carbon dioxide mixture to give a $\mathrm{pH}$ of 7.4 and perfused at a rate of $10 \mathrm{~mL} \mathrm{~min}^{-1}$ with a peristaltic pump (MS-Reglo 4 channels, Hugo Sachs Electronics) and kept at $37^{\circ} \mathrm{C}$. A latex balloon was introduced into the left ventricle via the left atrium and was pressurized with a spindle syringe until it reached a preload of $10 \mathrm{mmHg}$ to standardize cardiac work load. Heart rate (HR) and left ventricular end diastolic pressure (LVEDP) as well as the left ventricular developed pressure (LVDP, systolic minus end diastolic pressure) and coronary perfusion pressure (CPP) were monitored with a TPS Statham transducer and used to assess cardiac function.

2.9. Tissue Preparation. After perfusion protocol, the hearts were weighed and homogenized $(1.15 \% \mathrm{w} / \mathrm{v} \mathrm{KCl}$ and phenyl methyl sulphonyl fluoride PMSF $20 \mathrm{mmol} \mathrm{L}^{-1}$ ) in UltraTurrax. The suspension was centrifuged at $600 \mathrm{~g}$ for $10 \mathrm{~min}$ at $0-4^{\circ} \mathrm{C}$ to remove the nuclei and cell debris [20] and supernatants were used for the assay of nitric oxide metabolism and enzymatic activity. Cardiac tissue samples were rapidly removed after perfusion protocol and frozen at $-80^{\circ} \mathrm{C}$ for the evaluation of hydrogen peroxide steady state concentration.

2.10. Determination of Nitrates $\left(\mathrm{NO}_{3}{ }^{-}\right)$and Nitrites $\left(\mathrm{NO}_{2}{ }^{-}\right)$. Nitrites were determined using the Griess reagent, in which a chromophore with a strong absorbance at $540 \mathrm{~nm}$ is formed by reaction of nitrite with a mixture of naphthyletilenediamine $(0.1 \%)$ and sulphanilamide (1\%). The absorbance was measured in a spectrophotometer to give 
the nitrite concentration. Nitrates were determined as total nitrites (initial nitrite plus nitrite reduced from nitrate) after its reduction using nitrate reductase, from Aspergillus species in the presence of NADPH. A standard curve was established with a set of serial dilutions $\left(10^{-8}-10^{-3} \mathrm{~mol} \mathrm{~L}^{-1}\right)$ of sodium nitrite. Results were expressed as $\mathrm{mmol} \mathrm{L}^{-1}$ [21].

2.11. Determination of Hydrogen Peroxide. The assay was based in horseradish peroxidase (HRPO)-mediated oxidation of phenol red by hydrogen peroxide, leading to the formation of a compound that absorbs at $610 \mathrm{~nm}$. Tissues were incubated for $30 \mathrm{~min}$ at $37^{\circ} \mathrm{C}$ in phosphate buffer $10 \mathrm{mmol} \mathrm{L}^{-1}, \mathrm{NaCl} 140 \mathrm{mmol} \mathrm{L}^{-1}$, and dextrose $5 \mathrm{mmol} \mathrm{L}^{-1}$. The supernatants were transferred for tubes with phenol $0.28 \mathrm{mmol} \mathrm{L}^{-1}$ and $8.5 \mathrm{U} \mathrm{mL}^{-1}$ HRPO buffer, where, after 5 min incubation, $\mathrm{NaOH} 1 \mathrm{~N}$ was added and the mixture was read at $610 \mathrm{~nm}$. The results were expressed as nmoles $\mathrm{g}$ tissue $^{-1}[22]$.

2.12. Determination of Antioxidant Enzyme Activities. Superoxide dismutase (SOD) activity, expressed as $\mathrm{U}$ mg protein ${ }^{-1}$ of protein, was based on the inhibition of superoxide radical reaction with pyrogallol [23]. Catalase (CAT) activity was determined by following the decrease in $240 \mathrm{~nm}$ absorption of hydrogen peroxide $\left(\mathrm{H}_{2} \mathrm{O}_{2}\right)$. It was expressed as nmoles $\mathrm{mg}$ protein $^{-1}[24]$.

2.13. Determination of Protein Concentration. Protein was measured by the method of Lowry et al. [25], using bovine serum albumin as standard.

2.14. Statistical Analysis. Data were expressed as mean \pm S.D. and compared using two way ANOVA followed by StudentNewman-Keuls multiple comparison test. Values of $P<0.05$ were considered significant.

\section{Results}

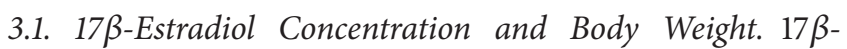
estradiol level was reduced significantly in OVX group (14.3 \pm $2.1 \mathrm{pg} \mathrm{mL}^{-1}$ ) as compared with SHAM, in diestrus phase $\left(30.7 \pm 5.6 \mathrm{pg} \mathrm{mL}^{-1}\right)$, and higher in OVX $+\mathrm{E}_{2}$ group $(63.3 \pm$ $\left.2.8 \mathrm{pg} \mathrm{mL}^{-1}\right)$. Body weight showed an opposite profile to $17 \beta$ estradiol concentration. OVX rats had significantly higher body weight than SHAM and OVX $+\mathrm{E}_{2}(252 \pm 10 ; 232 \pm 9$; and $210 \pm 7 \mathrm{~g}$, resp.).

3.2. Isolated Heart Perfusion. Tyrode-OVX rats have shown a significant increase in CPP $(32 \%$ and $28 \%$, resp.) before ischemia and after reperfusion when compared to SHAM. CPP did not differ significantly in OVX $+\mathrm{E}_{2}$ group before ischemia as compared to SHAM and OVX groups perfused with Tyrode (Figure 1). When NOS blockade by L-NAME was performed, CPP was increased in SHAM (54\% and $55 \%)$ and in OVX $+\mathrm{E}_{2}(22 \%$ and $18 \%)$ groups, respectively, before ischemia and after reperfusion as compared to their respective Tyrode control groups (Figure 1). The OVX groups

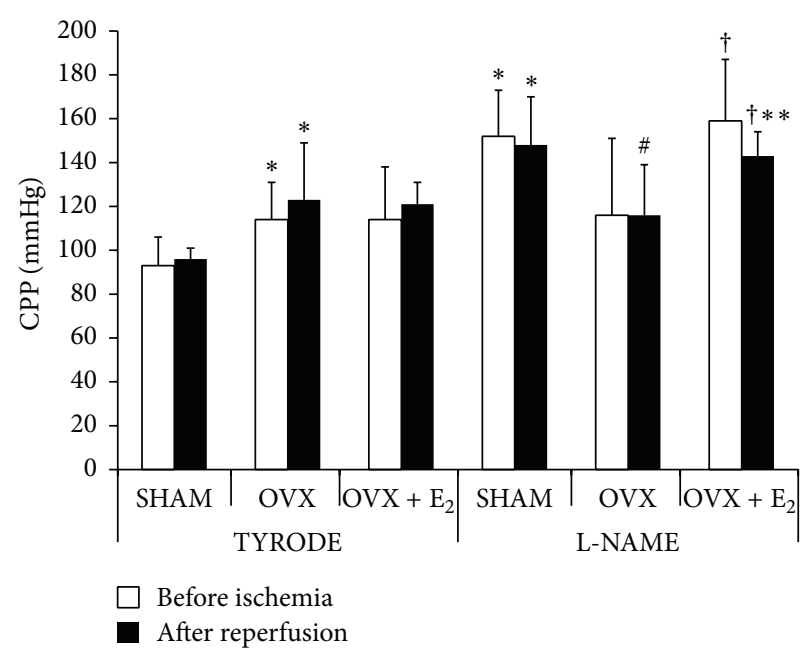

FIGURE 1: Coronary perfusion pressure (CPP) (in $\mathrm{mmHg}$ ) of the different experimental groups before ischemia and after reperfusion. Values are expressed as mean \pm S.D. of 4-6 animals/ group. * Significantly different from TYRODE-SHAM $(P<0.05)$; ${ }^{\#}$ significantly different from L-NAME-SHAM $(P<0.05)$; ${ }^{\dagger}$ significantly different from TYRODE-OVX $+\mathrm{E}_{2}(P<0.05) ;{ }^{* *}$ significantly different from L-NAME-OVX $(P<0.05)$.

showed no significant differences in CPP when comparing Tyrode and L-NAME perfusion. No significant differences were found in contractile function parameters (Table 1).

3.3. Determination of Nitrates $\left(\mathrm{NO}_{3}^{-}\right)$and Nitrites $\left(\mathrm{NO}_{2}^{-}\right)$and Hydrogen Peroxide $\left(\mathrm{H}_{2} \mathrm{O}_{2}\right)$. Nitrates/nitrites and hydrogen peroxide levels have shown the same profile of oscillation (Figures 2(a) and 2(b)). In animals perfused with Tyrode, both parameters were lower $35 \%$ in the OVX when compared to SHAM. In OVX $+\mathrm{E}_{2}$ these parameters increased $17 \%$ and $34 \%$, respectively, in comparison to OVX (Figures 2(a) and 2(b)). The L-NAME SHAM and OVX $+\mathrm{E}_{2}$ groups showed a decrease in the nitrates/nitrites levels by $22 \%$ and $18 \%$, respectively, and $\mathrm{H}_{2} \mathrm{O}_{2}$ levels by $36 \%$ and $30 \%$, respectively, as compared to their respective Tyrode control groups. No significant differences were found in these parameters evaluated in OVX groups.

3.4. Determination of Antioxidant Enzyme Activities. In the Tyrode perfused groups, CAT activity was elevated in the OVX group as compared to SHAM and was restored in $\mathrm{OVX}+\mathrm{E}_{2}$ group (Table 2). In the L-NAME perfused groups, SHAM and OVX $+\mathrm{E}_{2}$ showed an increased CAT activity $(19 \%$ and $31 \%$, resp.), when compared to their respective Tyrode control groups, reaching similar values than those observed in OVX groups, that did not exhibit alterations according to the solution utilized. No significant differences were found in SOD activity in the different experimental groups.

\section{Discussion}

The main finding of this study was to demonstrate that the protective role of estrogen in attenuating increased coronary 
TABLE 1: Contractile function of the different experimental groups before ischemia and after reperfusion.

\begin{tabular}{|c|c|c|c|c|c|c|}
\hline & \multicolumn{3}{|c|}{ Before Ischemia } & \multicolumn{3}{|c|}{ After Reperfusion } \\
\hline & HR (bpm) & LVEDP (mmHg) & LVDP (mmHg) & HR (bpm) & LVEDP (mmHg) & $\operatorname{LVDP}(\mathrm{mmHg})$ \\
\hline \multicolumn{7}{|l|}{ TYRODE } \\
\hline SHAM & $214 \pm 27$ & $10 \pm 1$ & $94 \pm 21$ & $188 \pm 27$ & $58 \pm 12$ & $21 \pm 9$ \\
\hline OVX & $201 \pm 38$ & $10 \pm 1$ & $87 \pm 20$ & $176 \pm 46$ & $63 \pm 23$ & $31 \pm 27$ \\
\hline $\mathrm{OVX}+\mathrm{E}_{2}$ & $184 \pm 31$ & $10 \pm 1$ & $95 \pm 15$ & $169 \pm 28$ & $62 \pm 24$ & $33 \pm 21$ \\
\hline \multicolumn{7}{|l|}{ L-NAME } \\
\hline SHAM & $202 \pm 39$ & $10 \pm 1$ & $100 \pm 15$ & $190 \pm 50$ & $55 \pm 21$ & $38 \pm 30$ \\
\hline OVX & $206 \pm 36$ & $9 \pm 1$ & $84 \pm 30$ & $195 \pm 31$ & $57 \pm 23$ & $32 \pm 19$ \\
\hline $\mathrm{OVX}+\mathrm{E}_{2}$ & $186 \pm 42$ & $10 \pm 1$ & $99 \pm 15$ & $165 \pm 58$ & $66 \pm 31$ & $36 \pm 29$ \\
\hline
\end{tabular}

Values are expressed as mean \pm S.D. of 4-6 animals/group. Heart rate (HR), left ventricle end diastolic pressure (LVEDP), left ventricular developed pressure (LVDP).

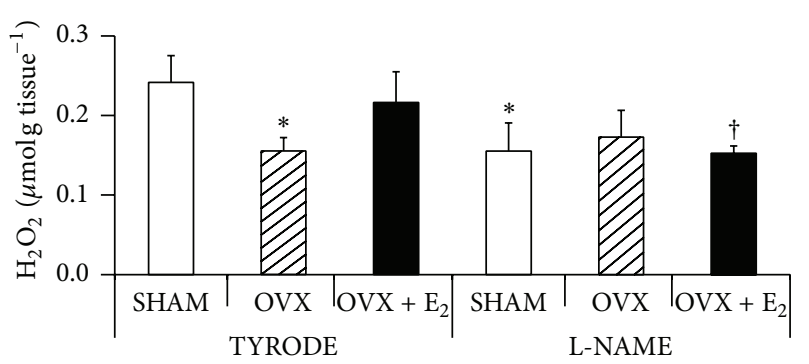

(a)

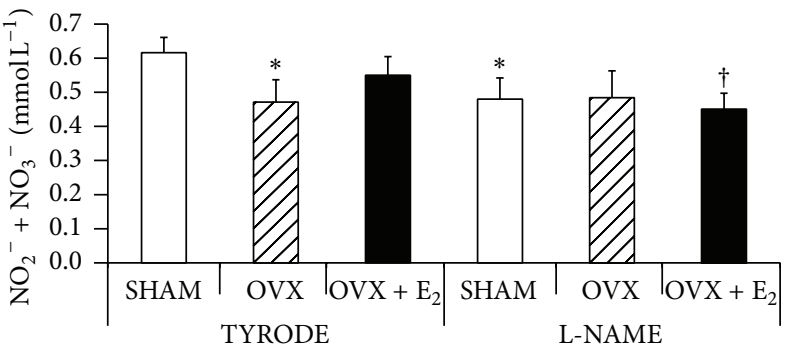

(b)

Figure 2: Hydrogen peroxide $\left(\mathrm{H}_{2} \mathrm{O}_{2}\right)$ concentration (in $\mu$ mol g tissue $\left.{ }^{-1}\right)$ in cardiac tissue slices (a) and nitrites $\left(\mathrm{NO}_{2}{ }^{-}\right)$and nitrates $\left(\mathrm{NO}_{3}{ }^{-}\right)$ concentration (in $\mathrm{mmol} \mathrm{L}^{-1}$ ) in cardiac muscle homogenates (b) of the different experimental groups at the end of reperfusion. Values are expressed as mean \pm S.D. of $4-6$ animals/group. ${ }^{*}$ Significantly different from TYRODE-SHAM $(P<0.05) ;{ }^{\dagger}$ significantly different from TYRODE-OVX $+\mathrm{E}_{2}(P<0.05)$.

TABLE 2: Antioxidant activity in cardiac muscle homogenates of the different experimental groups at the end of reperfusion.

\begin{tabular}{lcc}
\hline & $\begin{array}{c}\text { SOD } \\
\left(\text { U mg prot. }^{-1}\right)\end{array}$ & $\begin{array}{c}\text { CAT } \\
\text { (pmol mg prot. }^{-1} \text { ) }\end{array}$ \\
\hline TYRODE & & \\
SHAM & $13.3 \pm 2.0$ & $22.4 \pm 1.7$ \\
OVX & $11.7 \pm 0.9$ & $26.9 \pm 0.7^{*}$ \\
OVX $+\mathrm{E}_{2}$ & $11.9 \pm 1.2$ & $20.8 \pm 2.2^{* *}$ \\
L-NAME & & \\
SHAM & $14.4 \pm 1.7$ & $26.6 \pm 2.0^{*}$ \\
OVX & $12.0 \pm 0.7$ & $27.9 \pm 2.6$ \\
OVX $+\mathrm{E}_{2}$ & $12.2 \pm 2.8$ & $27.4 \pm 3.1^{\dagger}$ \\
\hline
\end{tabular}

Values are expressed as mean \pm S.D. of $4-6$ animals/group.

${ }^{*}$ significantly different from TYRODE-SHAM $(P<0.05) ;{ }^{* *}$ significantly different from TYRODE-OVX $(P<0.05)$; ${ }^{\dagger}$ significantly different from TYRODE-OVX $+\mathrm{E}_{2}(P<0.05)$.

resistance seems to be due to $\mathrm{NO}$ influence on the modulation of CAT activity and, by this way, regulating $\mathrm{H}_{2} \mathrm{O}_{2}$ concentration.

As expected, low estrogen levels were associated with higher coronary resistance in OVX group. The decrease in estrogen levels seems to impair the vascular tone regulation and, thus, has been associated with higher risk of cardiovascular disease [26]. In fact, an increased incidence of acute
MI in postmenopausal women has been observed [27]. This fact, combined with the prior knowledge of $\mathrm{H} 2 \mathrm{O} 2$ influence on coronary vascular bed by modulating the activity and expression of eNOS via the PI3-kinase and MAPK in-vitro [28], were the main reason to support our choice to develop this study utilizing the classical ex-vivo I/R model. To analyze the importance of estrogen in the coronary tone regulation in adverse heart situations, we simulated menopause by promoting bilateral ovariectomy and used ET to recover its levels. These procedures were effective in reducing and increasing, respectively, $17 \beta$-estradiol plasma concentration.

In accordance with the literature, the increase in vascular resistance in ovariectomized rats has been attributed, in part, to a lower NO bioavailability [29]. It has been shown that estrogen may act as an indirect coronary vasodilator mediated by endothelium-derived vasodilatory substances, such as NO [29]. Corroborating these findings, in this study we observed an opposite profile between nitrates/nitrites levels and CPP in the OVX group perfused with Tyrode. It is possible that, with the withdrawal of estrogen influence, endothelial dysfunction takes place, increasing coronary resistance [27]. When NO levels were increased by ET, the coronary resistance was attenuated in Tyrode-OVX $+\mathrm{E}_{2}$ group. This important role of estrogen in modulation of vascular tone appears to be mediated by PI3-kinase/Akt pathway in endothelial cells resulting in increased expression of NOS and leading to the greater production of NO [28]. 
Associated with the decrease in NO bioavailability, the OVX group also showed lower $\mathrm{H}_{2} \mathrm{O}_{2}$ levels as compared to SHAM perfused with Tyrode. The regulation of coronary tone is physiologically modulated in great part by NO. Additionally, numerous other molecules are involved in the regulation of vascular tone. Among these, the more prominent influence of $\mathrm{H}_{2} \mathrm{O}_{2}$ in pathological situations has been highlighted, when NO influence is reduced $[11,30]$. Therefore, the control of these substances appears to be an important mechanism involved in coronary tone regulation. Hydrogen peroxide, a downstream ROS also generate by NADPH-oxidase, has been suggested to be a key molecule in the regulation of the coronary tone by stimulating endothelium-dependent and/or endothelium independent vasorelaxation [30]. These effects, mediated by the regulation of smooth muscle's potassium channel and activation of eNOS, respectively, may represent a cellular adaptation in adverse situations, as in I/R [31, 32]. In this context, the estrogen influence in the vascular tone regulation also appears to be determined by less $\mathrm{H}_{2} \mathrm{O}_{2}$ production, since this hormone suppresses the activity and expression of NADPH oxidase [33]. In the present study, Tyrode-OVX group presented reduced $\mathrm{H}_{2} \mathrm{O}_{2}$ levels and higher CAT activity in relation to SHAM group after I/R. Although an inverse association between estrogen and ROS by suppression of the expression and activity of NADPH oxidase has been shown in the literature [33], the lower $\mathrm{H}_{2} \mathrm{O}_{2}$ levels, showed in this study, were associated with increased activity of CAT in ovariectomized group. Our findings corroborate previous findings of Behr et al. that showed an increase in peroxidases CAT and glutathione in ovariectomized rats [34]. A consequent adaptation of antioxidant enzymes appears to modulate the $\mathrm{H}_{2} \mathrm{O}_{2}$ levels and thus contribute to vascular tone regulation in rats with low estrogen levels.

Additionally, our findings suggest that this higher CAT activity seems to be resultant from the lower NO bioavailability in animals with reduced estrogen levels, since this group exhibited lower nitrates/nitrites levels. In fact, the antioxidant activity of CAT seems to be modulated by the NO levels. It has been shown in the literature that NO and CAT can quickly react and form a complex that culminate in reduction of $\mathrm{NO}$ bioavailability and reduced activity of catalase [35]. In order to determine the role of NO in the estrogen influence on coronary tone, L-NAME was added to the perfusion liquid. As expected, NOS blockade reduced significantly nitrates/nitrites levels in SHAM and OVX + $\mathrm{E}_{2}$ to values similar to those of OVX group. Furthermore, nitrates/nitrites were not modified in OVX groups perfused with Tyrode or L-NAME, reinforcing our suggestion of a reduced influence of $\mathrm{NO}$ in the regulation of coronary tone in ovariectomized rats. Associated with this, CAT was more effective to reduce $\mathrm{H}_{2} \mathrm{O}_{2}$ levels in SHAM and OVX $+\mathrm{E}_{2}$ groups perfused with L-NAME since its activity became less inhibited by NOS blockade. These results suggest that estrogen exerts its effects by its capacity to influence NOS activity.

Taken together, our data highlight the influence of estrogen on NOS and the CAT contribution in the regulation of $\mathrm{NO}$ and $\mathrm{H}_{2} \mathrm{O}_{2}$ levels to an important joint action in the control of coronary resistance. Regulating these parameters by negative feedback mechanism, CAT emerges as a key molecule in the regulatory control of the coronary tone. Moreover, the increase in its activity with reduced NO levels suggests a significant influence of $\mathrm{H}_{2} \mathrm{O}_{2}$ as vasomodulator in adverse situations. This knowledge may be relevant in the proposal of therapeutical strategies capable to diminish the adverse effects observed in the I/R syndrome.

\section{Conflict of Interests}

The authors declare that there is no conflict of interest that could be perceived as prejudicing the impartiality of the research reported.

\section{Acknowledgments}

This work was supported by CNPq and FAPERGS, Brazilian Research Agencies. The authors would like to acknowledge Weinmann Clinical Analysis Laboratory for $17 \beta$-estradiol hormone measurements.

\section{References}

[1] M. E. Mendelsohn and R. H. Karas, "The protective effects of estrogen on the cardiovascular system," New England Journal of Medicine, vol. 340, no. 23, pp. 1801-1811, 1999.

[2] M. C. Solimene, "Coronary heart disease in women: a challenge for the 21st century," Clinics, vol. 65, no. 1, pp. 99-106, 2010.

[3] T. Simoncini and A. R. Genazzani, "Non-genomic actions of sex steroid hormones," European Journal of Endocrinology, vol. 148, no. 3, pp. 281-292, 2003.

[4] M. G. Perrelli, P. Pagliaro, and C. Penna, "Ischemia/reperfusion injury and cardioprotective mechanisms: role of mitochondria and reactive oxygen species," World Journal of Cardiology, vol. 3, pp. 186-200, 2011.

[5] M. K. Misra, M. Sarwat, P. Bhakuni, R. Tuteja, and N. Tuteja, "Oxidative stress and ischemic myocardial syndromes," Medical Science Monitor, vol. 15, no. 10, pp. RA209-RA219, 2009.

[6] J. L. Mehta, W. W. Nichols, W. H. Donnelly, D. L. Lawson, and T. G. P. Saldeen, "Impaired canine coronary vasodilator response to acetylcholine and bradykinin after occlusion-reperfusion," Circulation Research, vol. 64, no. 1, pp. 43-54, 1989.

[7] S. Pou, W. S. Pou, D. S. Bredt, S. H. Snyder, and G. M. Rosen, "Generation of superoxide by purified brain nitric oxide synthase," Journal of Biological Chemistry, vol. 267, no. 34, pp. 24173-24176, 1992.

[8] I. Huk, J. Nanobashvili, C. Neumayer et al., "L-arginine treatment alters the kinetics of nitric oxide and superoxide release and reduces ischemia/reperfusion injury in skeletal muscle," Circulation, vol. 96, no. 2, pp. 667-675, 1997.

[9] J. L. Zweier, J. Fertmann, and G. Wei, "Nitric oxide and peroxynitrite in postischemic myocardium," Antioxidants and Redox Signaling, vol. 3, no. 1, pp. 11-22, 2001.

[10] T. Yada, H. Shimokawa, O. Hiramatsu et al., "Cardioprotective role of endogenous hydrogen peroxide during ischemiareperfusion injury in canine coronary microcirculation in vivo," The American Journal of Physiology-Heart and Circulatory Physiology, vol. 291, no. 3, pp. H1138-H1146, 2006.

[11] F. Cosentino, J. E. Barker, M. P. Brand et al., "Reactive oxygen species mediate endothelium-dependent relaxations in 
Tetrahydrobiopterin-deficient mice," Arteriosclerosis, Thrombosis, and Vascular Biology, vol. 21, no. 4, pp. 496-502, 2001.

[12] E. A. Booth and B. R. Lucchesi, "Estrogen-mediated protection in myocardial ischemia-reperfusion injury," Cardiovascular Toxicology, vol. 8, no. 3, pp. 101-113, 2008.

[13] P. Zhai, T. E. Eurell, R. Cotthaus, E. H. Jeffery, J. M. Bahr, and D. R. Gross, "Effect of estrogen on global myocardial ischemiareperfusion injury in female rats," The American Journal of Physiology-Heart and Circulatory Physiology, vol. 279, no. 6, pp. H2766-H2775, 2000.

[14] R. Tissier, X. Waintraub, N. Couvreur et al., "Pharmacological postconditioning with the phytoestrogen genistein," Journal of Molecular and Cellular Cardiology, vol. 42, no. 1, pp. 79-87, 2007.

[15] M. Florian, A. Freiman, and S. Magder, "Treatment with 17$\beta$-estradiol reduces superoxide production in aorta of ovariectomized rats," Steroids, vol. 69, no. 13-14, pp. 779-787, 2004.

[16] M. Elisa Prediger, G. Duzzo Gamaro, L. MacHado Crema, F. Urruth Fontella, and C. Dalmaz, "Estradiol protects against oxidative stress induced by chronic variate stress," Neurochemical Research, vol. 29, no. 10, pp. 1923-1930, 2004.

[17] F. K. Marcondes, F. J. Bianchi, and A. P. Tanno, "Determination of the estrous cycle phases of rats: some helpful considerations," Brazilian Journal of Biology, vol. 62, no. 4, pp. 609-614, 2002.

[18] A. S. D. R. Araujo, M. F. S. De Miranda, U. De Oliveira et al., "Increased resistance to hydrogen peroxide-induced cardiac contracture is associated with decreased myocardial oxidative stress in hypothyroid rats," Cell Biochemistry and Function, vol. 28, no. 1, pp. 38-44, 2010.

[19] H. Han, R. Kaiser, K. Hu, M. Laser, G. Ertl, and J. Bauersachs, "Selective modulation of endogenous nitric oxide formation in ischemia/reperfusion injury in isolated rat hearts: effects on regional myocardial flow and enzyme release," Basic Research in Cardiology, vol. 98, no. 3, pp. 165-174, 2003.

[20] S. F. Llesuy, J. Milei, and H. Molina, "Comparison of lipid peroxidation and myocardial damage induced by adriamycin and $4^{\prime}$-epiadriamycin in mice," Tumori, vol. 71, no. 3, pp. 241249, 1985.

[21] D. L. Granger, N. M. Anstey, W. C. Miller, and J. B. Weinberg, "Measuring nitric oxide production in human clinical studies," Methods in Enzymology, vol. 301, pp. 49-61, 1998.

[22] E. Pick and Y. Keisari, "A simple colorimetric method for the measurement of hydrogen peroxide produced by cells in culture," Journal of Immunological Methods, vol. 38, no. 1-2, pp. 161-170, 1980.

[23] S. L. Marklund, "Superoxide dismutase isoenzymes in tissues and plasma from New Zealand black mice, nude mice and normal BALB/c mice," Mutation Research, vol. 148, no. 1-2, pp. 129-134, 1985.

[24] H. Aebi, "Catalase in vitro," Methods in Enzymology, vol. 105, pp. 121-126, 1984.

[25] O. H. Lowry, N. J. Rosebrough, A. L. Farr, and R. J. Randall, "Protein measurement with the Folin phenol reagent," The Journal of Biological Chemistry, vol. 193, no. 1, pp. 265-275, 1951.

[26] H. R. Lee, T. H. Kim, and K. C. Choi, "Functions and physiological roles of two types of estrogen receptors, ERalpha and ERbeta, identified by estrogen receptor knockout mouse," Laboratory Animal Research, vol. 28, pp. 71-76, 2012.

[27] A. A. Knowlton and A. R. Lee, "Estrogen and the cardiovascular system," Pharmacology \& Therapeutics, vol. 135, pp. 54-70, 2012.

[28] G. Han, H. Ma, R. Chintala et al., "Nongenomic, endotheliumindependent effects of estrogen on human coronary smooth muscle are mediated by type I (neuronal) NOS and PI3-kinaseAkt signaling," The American Journal of Physiology-Heart and Circulatory Physiology, vol. 293, no. 1, pp. H314-H321, 2007.

[29] I. Hernández, J. L. Delgado, L. F. Carbonell, M. C. Pérez, and T. Quesada, "Hemodynamic effect of $17 \beta$-estradiol in absence of NO in ovariectomized rats: role of angiotensin II," The American Journal of Physiology-Regulatory Integrative and Comparative Physiology, vol. 274, no. 4, pp. R970-R978, 1998.

[30] H. Cai, Z. Li, M. E. Davis, W. Kanner, D. G. Harrison, and S. C. Dudley Jr., "Akt-dependent phosphorylation of serine 1179 and mitogen-activated protein kinase kinase/extracellular signal-regulated kinase 1/2 cooperatively mediate activation of the endothelial nitric-oxide synthase by hydrogen peroxide," Molecular Pharmacology, vol. 63, no. 2, pp. 325-331, 2003.

[31] H. Cai, J. S. McNally, M. Weber, and D. G. Harrison, "Oscillatory shear stress upregulation of endothelial nitric oxide synthase requires intracellular hydrogen peroxide and CaMKII," Journal of Molecular and Cellular Cardiology, vol. 37, no. 1, pp. 121-125, 2004.

[32] J. Cheng, X. Ma, J. Zhang, and D. Su, "Diverse modulating effects of estradiol and progesterone on the monophasic action potential duration in Langendorff-perfused female rabbit hearts," Fundamental and Clinical Pharmacology, vol. 26, no. 2, pp. 219-226, 2012.

[33] A. A. Miller, G. R. Drummond, A. E. Mast, H. H. H. W. Schmidt, and C. G. Sobey, "Effect of gender on NADPH-oxidase activity, expression, and function in the cerebral circulation: role of estrogen," Stroke, vol. 38, no. 7, pp. 2142-2149, 2007.

[34] G. A. Behr, C. E. Schnorr, and J. C. F. Moreira, "Increased blood oxidative stress in experimental menopause rat model: the effects of vitamin A low-dose supplementation upon antioxidant status in bilateral ovariectomized rats," Fundamental and Clinical Pharmacology, vol. 26, no. 2, pp. 235-249, 2012.

[35] G. C. Brown, "Reversible binding and inhibition of catalase by nitric oxide," European Journal of Biochemistry, vol. 232, no. 1, pp. 188-191, 1995. 


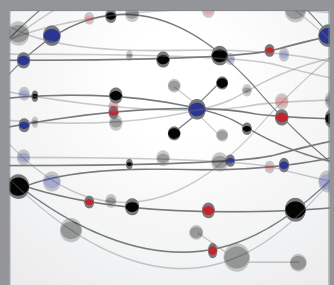

The Scientific World Journal
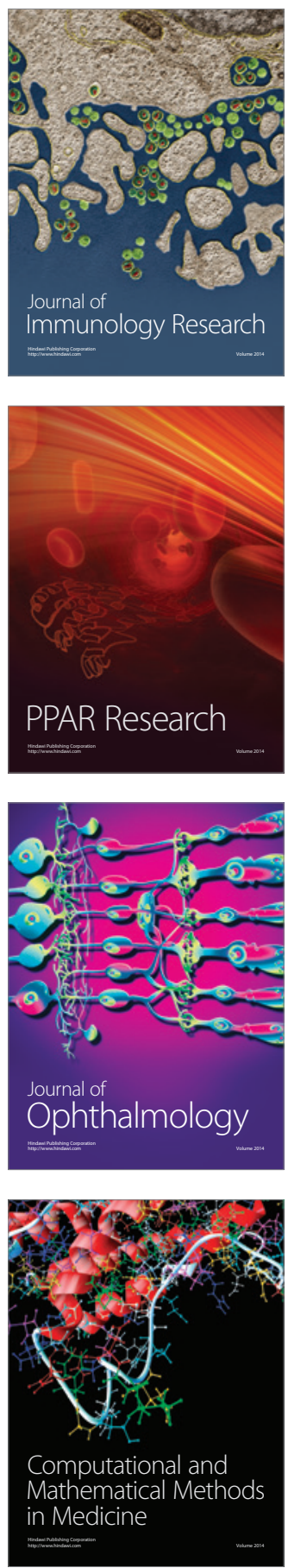

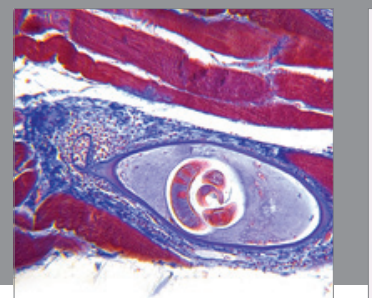

Gastroenterology

Research and Practice
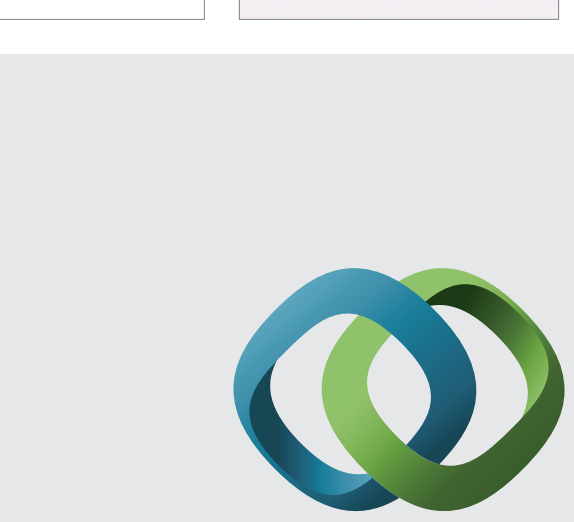

\section{Hindawi}

Submit your manuscripts at

http://www.hindawi.com
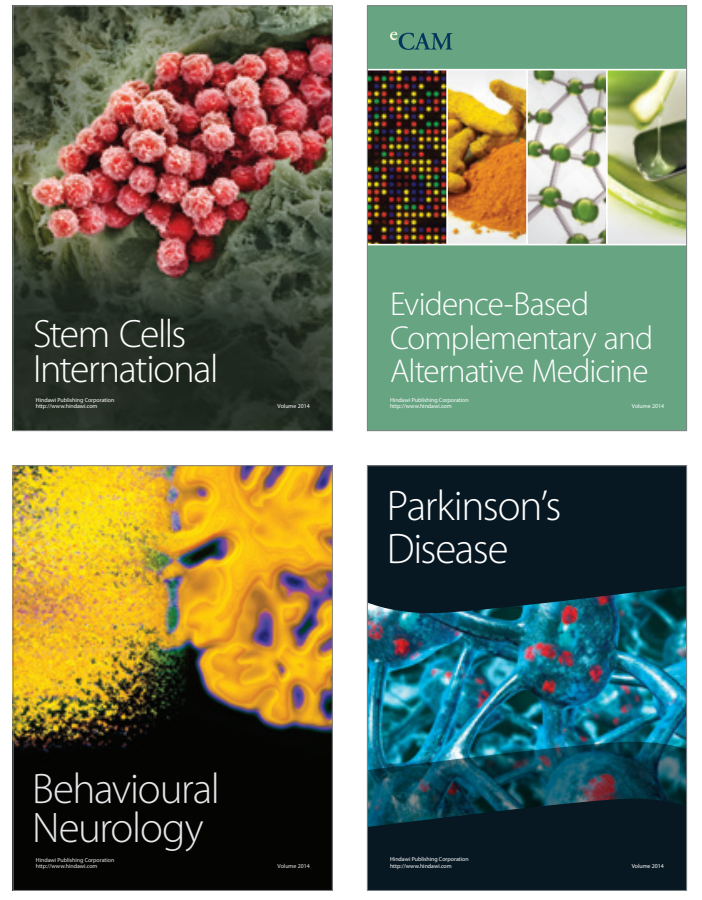
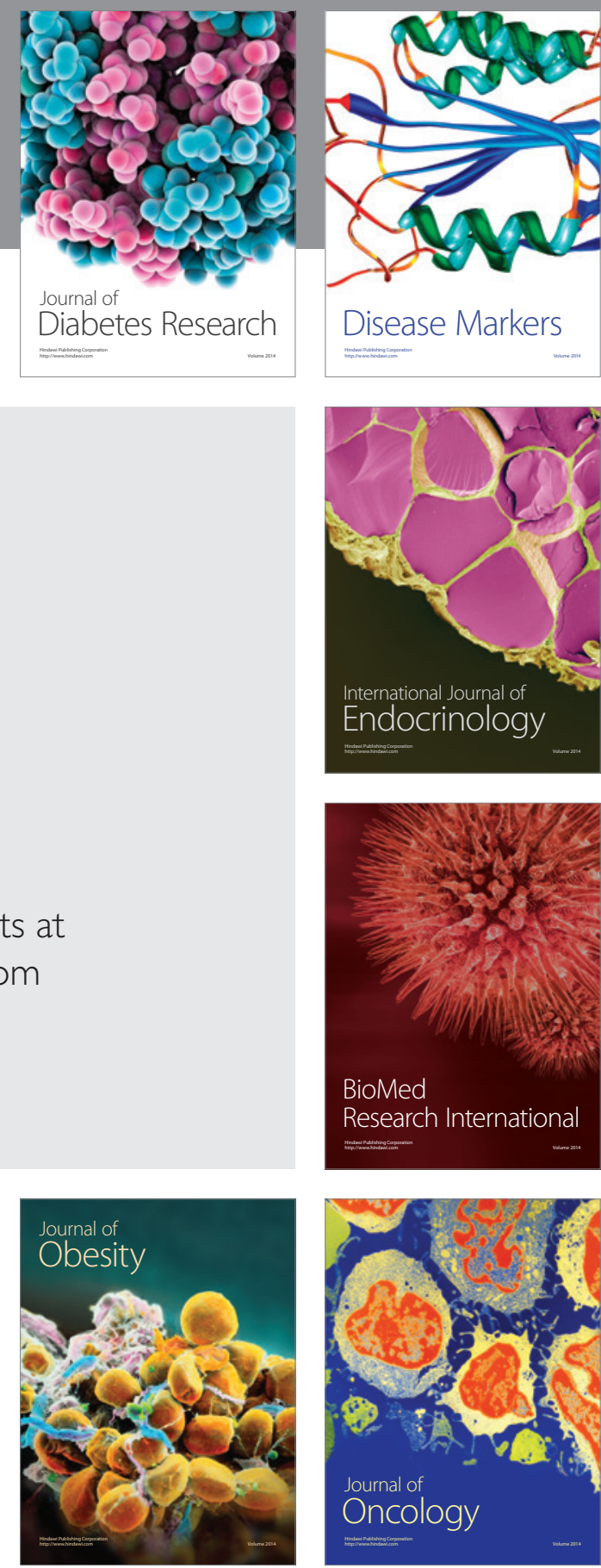

Disease Markers
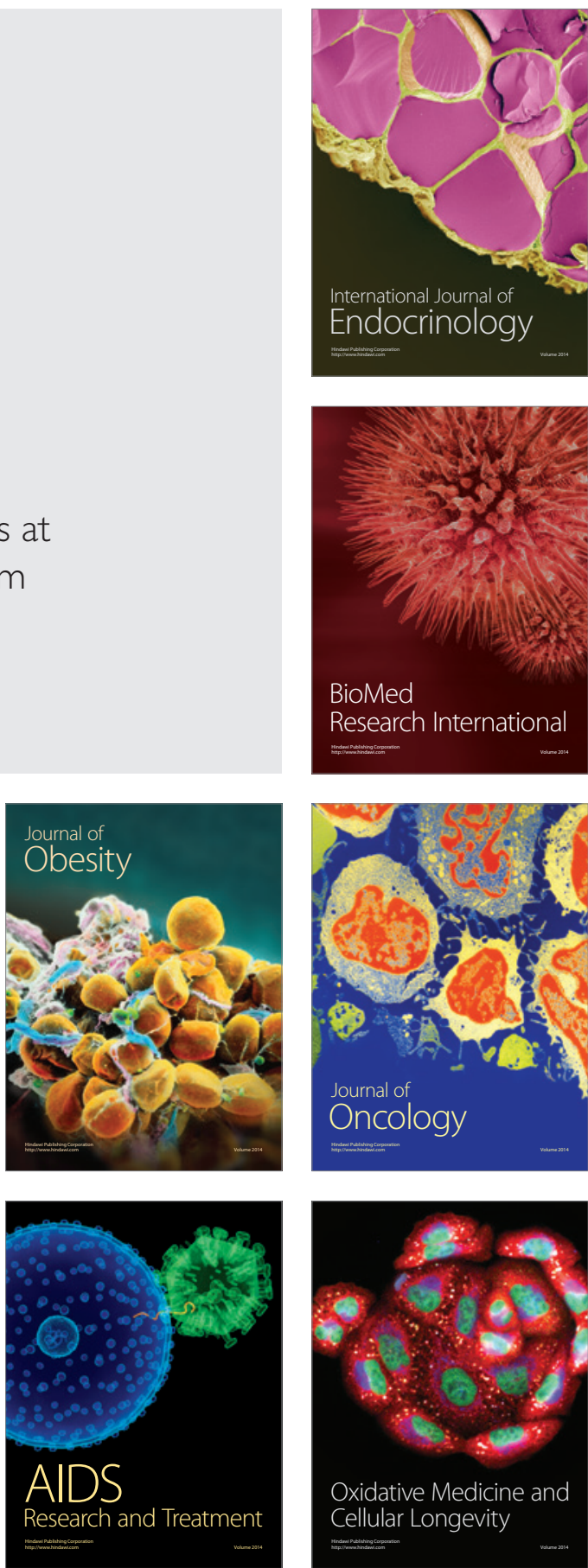